\title{
Associations between executive functioning, coping, and psychosocial functioning after acquired brain injury
}

Citation for published version (APA):

Wolters Gregório, G. H. T., Ponds, R. W. H. M., Smeets, S. M. J., Jonker, F., Pouwels, C. G. J. G., Verhey, F. R. J., \& van Heugten, C. M. (2015). Associations between executive functioning, coping, and psychosocial functioning after acquired brain injury. British Journal of Clinical Psychology, 54(3), $291-306$. https://doi.org/10.1111/bjc.12074

Document status and date:

Published: 01/09/2015

DOI:

10.1111/bjc. 12074

Document Version:

Publisher's PDF, also known as Version of record

Document license:

Taverne

Please check the document version of this publication:

- A submitted manuscript is the version of the article upon submission and before peer-review. There can be important differences between the submitted version and the official published version of record.

People interested in the research are advised to contact the author for the final version of the publication, or visit the DOI to the publisher's website.

- The final author version and the galley proof are versions of the publication after peer review.

- The final published version features the final layout of the paper including the volume, issue and page numbers.

Link to publication

\footnotetext{
General rights rights.

- You may freely distribute the URL identifying the publication in the public portal. please follow below link for the End User Agreement:

www.umlib.nl/taverne-license

Take down policy

If you believe that this document breaches copyright please contact us at:

repository@maastrichtuniversity.nl

providing details and we will investigate your claim.
}

Copyright and moral rights for the publications made accessible in the public portal are retained by the authors and/or other copyright owners and it is a condition of accessing publications that users recognise and abide by the legal requirements associated with these

- Users may download and print one copy of any publication from the public portal for the purpose of private study or research.

- You may not further distribute the material or use it for any profit-making activity or commercial gain

If the publication is distributed under the terms of Article $25 \mathrm{fa}$ of the Dutch Copyright Act, indicated by the "Taverne" license above, 


\title{
Associations between executive functioning, coping, and psychosocial functioning after acquired brain injury
}

\author{
Gisela Wolters Gregório',2, Rudolf W. H. M. Ponds' ${ }^{1,3}$, \\ Sanne M. J. Smeets', Frank Jonker ${ }^{4}$, Climmy G. J. G. Pouwels ${ }^{2}$, \\ Frans R. Verhey' and Caroline M. van Heugten ${ }^{1,5 *}$ \\ 'Faculty of Health, Medicine and Life Sciences, Department of Psychiatry and \\ Neuropsychology, School for Mental Health and Neuroscience, Maastricht \\ University, The Netherlands \\ ${ }^{2}$ Department ABI Huize Padua, GGZ Oost Brabant, Boekel, The Netherlands \\ ${ }^{3}$ Adelante, Rehabilitation Centre, Hoensbroek, The Netherlands \\ ${ }^{4}$ Department Vesalius, Altrecht GGZ, Den Dolder, The Netherlands \\ ${ }^{5}$ Faculty of Psychology and Neuroscience, Department of Neuropsychology and \\ Psychopharmacology, Maastricht University, The Netherlands
}

Objectives. To examine the relationships between executive functioning, coping, depressive symptoms, and quality of life in individuals with neuropsychiatric symptoms after acquired brain injury $(A B I)$.

Design. Cross-sectional study.

Methods. Individuals $(n=93)$ in the post-acute and chronic phase ( $>3$ months $)$ after $A B I$ and their significant others $(N=58)$ were recruited from outpatient clinics of four mental health centres in the Netherlands. Outcome measures were the Trail Making Test, Stroop Colour Word Test, Frontal Systems Behavioural Scale, Utrecht Coping List, Patient Health Questionnaire, and Life Satisfaction Questionnaire. Data were analysed with multiple regression analyses.

Results. Self-reported executive dysfunction was associated with greater use of passive coping styles $(\beta=.37, p<.01)$, and passive coping, in turn, was associated with lower quality of life $(\beta=-.57, p<.001)$ and more depressive symptoms $(\beta=.65, p<.00 \mathrm{I})$. Problem-focused coping was associated with higher quality of life among individuals who reported better executive functioning $(\beta=-.94, p<.05)$. Performances on executive functioning tests were not associated with coping, depressive symptoms, or quality of life.

Conclusions. For clinicians, these data indicate that individuals who report greater difficulties with executive functioning after $A B I$ are inclined to use maladaptive passive coping styles, which should be targeted in treatment. In comparison, individuals who report greater difficulties with executive functioning should not be prompted to use problem-focused coping styles. These individuals may benefit from

\footnotetext{
*Correspondence should be addressed to Caroline M. van Heugten, Maastricht University, Department of Psychiatry and Neuropsychology, School for Mental Health and Neuroscience, P.O. Box 616 (drt / 2), 6200 MD Maastricht, The Netherlands (email: c.vanheugten@maastrichtuniversity.nl).
} 
other coping styles, such as the use of seeking social support or acceptance of problems.

\section{Practitioner points}

- Coping influences the association between executive functioning and quality of life.

- Individuals who report difficulties with executive functioning after $A B I$ may be inclined to use passive coping styles, which are maladaptive.

- Problem-focused coping strategies may be more useful for individuals who have strong executive abilities.

- This study was a cross-sectional study; thus, a cause-and-effect relationship could not be established between executive functioning, coping, and psychosocial functioning.

- As this research was part of standard clinical care, non-traditional tests for executive functioning were not administered.

Acquired brain injury (ABI) can have long-term impacts on cognitive, emotional, behavioural, and motor functioning (Consensus Conference, 1999). Although some patients adjust well following ABI, others experience long-lasting adaption difficulties in their daily life. This phenomenon cannot be explained solely by injury characteristics. Coping models have been used to explain the adjustment process after ABI (Folkman, Lazarus, Gruen, \& DeLongis, 1986, p. 574; Godfrey, Knight, \& Partridge, 1996; Kendall \& Terry, 1996; Moore \& Stambrook, 1995). These models suggest that in stressful situations, coping strategies are intended to have a stress-reducing effect. The use of emotion-focused coping styles, such as passive coping styles and avoidance, has been shown to be maladaptive for mood and quality of life in the chronic phase post-ABI (Dawson, Schwartz, Winocur, \& Stuss, 2007; Wolters, Stapert, Brands, \& van Heugten, 2010). Alternatively, the use of problem-focused coping, such as actively managing problems, has been associated with adaptive functioning, although evidence for this association is less consistent (Anson \& Ponsford, 2006).

Researchers have found that patients with ABI more often use passive, emotionfocused coping and less often use problem-focused coping styles than the general population (Wolters, Stapert, Brands, \& van Heugten, 2011). Some researchers have shown that patients with $\mathrm{ABI}$ with executive dysfunction reported less frequent use of problem-focused coping styles than patients with better executive functioning (Kegel, Dux, \& Macko, 2014; Krpan, Levine, Stuss, \& Dawson, 2007). These researchers concluded that individuals with executive deficits do not have the cognitive ability to use coping strategies that require problem-solving skills; thus, they consequently rely on emotion-focused coping styles. It could therefore be hypothesized that patients with executive deficits who do use problem-focused coping styles have worse outcomes. However, this hypothesis has not yet been investigated. Two other studies have not found associations between executive functioning and coping (Spitz, Schonberger, \& Ponsford, 2013; Wolters et al., 2011).

A vast body of research has been performed investigating the direct effects of executive functioning on psychological and emotional adjustment (Benedictus, Spikman, \& van der Naalt, 2010; Ponsford, Draper, \& Schonberger, 2008; Spitz, Ponsford, Rudzki, \& Maller, 2012). Little information is known about the indirect associations between executive functioning and outcome. To our knowledge, only two studies have investigated the moderating and mediating effects of coping on this association (Spitz et al., 2013; Wood \& Rutterford, 2006). Moderation occurs when coping changes the 
strength or direction of the relationship between executive functioning and outcome. For example, executive functioning could have a stronger or weaker effect on outcome in patients who display a certain coping style. Mediation occurs when level of executive functioning determines the use of a particular coping style, which in turn influences outcome. For example, executive dysfunction could interfere with the adequate use of problem-focused coping styles, which in turn could lead to a worse outcome. No evidence was found for either a moderating or mediating effect of coping on the association between executive functioning and outcome.

This may be partly explained because some individuals who score in the normal range on tests of executive functioning may still experience executive deficits in their daily life (Boelen, Spikman, Rietveld, \& Fasotti, 2009; Burgess et al., 2006). Both clinicians and researchers face major difficulties in identifying individuals who experience executive problems in daily life. A recent review investigated the psychometric properties of executive functioning assessments used after $\mathrm{ABI}$ and showed that of the 104 correlations between executive measures, only 5 were higher than .5 (Mueller \& Dollaghan, 2013). Pearson correlations in the range of $0.2-0.5$ were observed in a study investigating the ecological validity of 10 common measures of executive functioning (Burgess, Alderman, Evans, Emslie, \& Wilson, 1998). Many experimental and neuropsychological measures focus on measuring cognitive constructs (e.g., executive functioning) with little consideration for how these measures relate to everyday functioning (Hanna-Pladdy, 2007). Self-report measures may provide additional information on executive problems patients encounter in daily life (Bennett, Ong, \& Ponsford, 2005). Although there is no consensus about the most accurate way of measuring executive functioning, self-report measures may provide additional useful information about executive functioning that cannot be captured with standard neuropsychological assessments (Bennett et al., 2005; Boelen et al., 2009).

Until now, research studies on coping after ABI have mainly focused on individuals whose most prominent symptoms were motor or cognitive. Patients with neuropsychiatric symptoms after ABI, including depression, anxiety, and aggression, are often excluded from these studies, possibly because of their increased symptom complexity and the high prevalence of comorbidity (Dawson et al., 2007; Finset \& Andersson, 2000; Johnston \& Hall, 1994; Krpan et al., 2007). However, these patients frequently appeal to mental health care, have trouble reintegrating into the community, and require long-term care and support (Bryant et al., 2010; Rao \& Lyketsos, 2000). For treatment purposes, it is important to gain knowledge of the underlying factors, such as executive functioning and coping, that are related to emotional and psychosocial outcomes in these individuals. To our knowledge, only one coping study has included patients with depression and anxiety after traumatic brain injury (TBI), and it found that emotion-focused coping was related to more maladaptive 1-year psychosocial outcomes on the Glasgow Outcome ScaleExtended (Gould, Ponsford, Johnston, \& Schonberger, 2011).

This study used a cross-sectional design to examine a group of individuals with ABI who were referred to outpatient mental health clinics because of neuropsychiatric symptoms. First, we investigated whether the patients used different coping styles than the general population. Second, we explored the associations between demographics, injury characteristics, coping, executive functioning, depressive symptoms, and quality of life. Third, we studied the direct, mediated, and moderated relationships between coping, executive functioning, depressive symptoms, and quality of life. A combination of standardized tests and a self-report questionnaire was used to measure executive functioning. 
We expected that patients would report less problem-focused and more passive coping than the general population. In addition, we hypothesized that there would be significant associations between coping, executive functioning, depressive symptoms, and quality of life. Based on the coping models from Folkman et al. (1986), Godfrey et al. (1996), Kendall and Terry (1996), and Moore and Stambrook (1995), we expected that coping would mediate the influence of executive functioning on depressive symptoms and quality of life. More specifically, we predicted that patients with cognitive impairment would less often use problem-focused coping and more often use emotion-focused coping, which is maladaptive. We explored the hypothesis that coping would moderate the relationships between executive functioning and depressive symptoms and quality of life. More specifically, we hypothesized that patients with executive impairments who reported using problem-focused coping styles more often would report higher levels of depressive symptoms and a lower quality of life.

\section{Method}

\section{Participants}

Participants were recruited during the period from September 2010 to January 2012. The sample consisted of patients with ABI who were consecutively admitted to outpatient clinics in four participating mental health centres in the Netherlands due to neuropsychiatric symptoms following ABI and their significant others (SOs). The criteria for patients to be admitted to these centres were comparable, as were the rehabilitation methods used. All patients suffered from ABI and at least one neuropsychiatric symptom (e.g., aggression, irritability, apathy). Patients were included in this study if they were 18 years or older and at least 3 months had passed since their brain injury. Patients were excluded if they had an insufficient command of the Dutch language, if they were unable to complete the questionnaires on the basis of clinical judgment, or if they suffered from degenerative brain disease or whiplash. SOs were included if they were 18 years or older, knew the patient well, and had frequent contact with the patient. SOs were excluded if they had an insufficient command of the Dutch language, were unable to complete the questionnaires based on clinical judgment, or had a neurological or psychiatric disorder. Some patients did not have an SO, some SOs did not want to participate in the study, and others did not fulfil the criteria. Consequently, fewer SOs than patients were included in the study. All participants signed an informed consent to use their clinical and test data for scientific research.

In total, 93 patients and 58 SOs participated in the study. Table 1 shows the demographic and injury characteristics of the patients. Most patients had injuries to multiple brain regions (43\%), followed by injuries in parietal brain regions (10\%) and frontal brain regions (8\%). The mean Global Assessment of Functioning (GAF; 54.5) indicated moderate psychiatric symptoms (e.g., flat affect and circumstantial speech) or moderate difficulty in social, occupational, or school functioning (e.g., few friends, conflicts with peers). Approximately $71 \%$ of the participants used one or more medications, with the majority of participants using antidepressants (61\%) or other medications (83\%), such as medication for somatic complaints. The majority of participants fit the diagnostic criteria for a cognitive disorder as a first DSM-IV diagnosis (82\%). Patients were most often referred to the centres by general practitioners (46\%) and psychiatrists (22\%). Generally, they were referred for clinical consultation and treatment. 
Table I. Patient characteristics $(N=93)$

\begin{tabular}{|c|c|c|}
\hline & Mean $(S D)$ & Range \\
\hline Age & $45.5(12.7)$ & $19.0-76.2$ \\
\hline Years post-injury & $11.2(11.1)$ & $0.3-41.9$ \\
\hline $\operatorname{GAF}(n=92)$ & $\begin{array}{c}54.5(7.2) \\
\%\end{array}$ & $30-70$ \\
\hline Male & 68 & \\
\hline \multicolumn{3}{|l|}{ Educational level } \\
\hline Low & 75 & \\
\hline High & 25 & \\
\hline \multicolumn{3}{|l|}{ Type of referral } \\
\hline General practitioners & 46 & \\
\hline Psychiatrists & 22 & \\
\hline Psychologists & 11 & \\
\hline Rehabilitation specialists & 10 & \\
\hline Other ${ }^{\mathrm{a}}$ & 12 & \\
\hline \multicolumn{3}{|l|}{ Type of brain injury } \\
\hline Traumatic & 45 & \\
\hline Vascular & 30 & \\
\hline Tumour & 8 & \\
\hline Intoxication & 4 & \\
\hline Multiple & 5 & \\
\hline Other ${ }^{\mathrm{b}}$ & 8 & \\
\hline \multicolumn{3}{|l|}{ Side of brain injury } \\
\hline Left & 19 & \\
\hline Right & 23 & \\
\hline Bilateral & 37 & \\
\hline Not specified & 22 & \\
\hline Psychopharmacological medication, yes & 71 & \\
\hline Antipsychotics & 10 & \\
\hline Antidepressants & 61 & \\
\hline Anxiolytics & 31 & \\
\hline Lithium & 0 & \\
\hline Psychostimulants & 3 & \\
\hline Sedatives & 16 & \\
\hline Hypnotics & 3 & \\
\hline Other ${ }^{c}$ & 83 & \\
\hline
\end{tabular}

Note. GAF, Global Assessment of Functioning.

${ }^{a}$ Company doctors, psychiatric nurses, and support services.

${ }^{\text {bAnoxia }}(n=1)$, inflammation $(n=3)$, not specified $(n=3)$.

'Such as medication for somatic complaints.

\section{Procedure}

A neuropsychologist screened participants during the regular intake process of the given clinic. Eligible participants received an information letter from the neuropsychologist with an explanation of the study. The following information was collected from the patients' medical files: Age, educational level, gender, injury type and severity, location of injury, DSM-IV diagnosis, GAF, type of referral, and use of psychopharmacological medications. Information on injury severity was not recorded consistently in the medical files; accordingly, these data could not be collected meaningfully. 
Educational level was assessed according to the standardized Dutch schooling system (De Bie, 1987). The categories were reduced to low (1-4) and high (5-8) education. The GAF is a clinical judgment of an individual's symptoms and level of psychological, social, and occupational functioning, with scores ranging from 0 to 100 . Higher scores represent fewer symptoms, that is a higher level of functioning (American Psychiatric Association, 2000). A psychiatrist or psychologist, in collaboration with other members of the multidisciplinary team, had rated this scale as part of the intake procedure, to provide a global judgment of the functioning of the patient. The patients completed a neuropsychological assessment including neuropsychological tests and self-report questionnaires as part of standard clinical care. SOs completed two additional selfreport questionnaires.

The Medical Ethics Committee in the Netherlands and the Research Committees of each of the four institutions approved the study procedures.

\section{Measurements}

Trail Making Test (TMT)

The TMT tasks assess scanning, motor function, letter and number recognition, and mental flexibility (Rabin, Barr, \& Burton, 2005; Schmand, Houx, \& de Koning, 2003; Spreen \& Strauss, 1998; Tombaugh, 2004). A ratio score is calculated (i.e., time on card B divided by time on card A) and provides an indicator of executive functioning. More specifically, it is a measure of mental flexibility (TMT). The norms from Schmand et al. (2003) were used to classify the patients' scores. Scores higher than three indicated difficulties in mental flexibility (Arbuthnott \& Frank, 2000).

\section{Stroop Colour Word Test (SCWT)}

The SCWT measures speed of information processing and the capacity to suppress automatic response tendencies (Stroop, 1935). The times on card 1, card 2, and card 3 were collected. These times were then used to calculate an interference score (mean time on card I and II subtracted from mean time on card III) that served as another index of executive functioning, specifically response inhibition (Stroop; Valentijn et al., 2005). The norms from Schmand et al. (2003) were used to classify the patients' scores. Scores lower than $2 S D$ from the mean indicated difficulties in response inhibition.

\section{Frontal Systems Behavioural Scale (FrSBe)}

The FrSBe is a 46-item behaviour rating scale intended to measure behaviour associated with damage to the frontal systems of the brain (Grace \& Malloy, 2001). In this study, we used the Executive Dysfunction subscale, which was completed by both the patient (FrSBe-P) and the SO (FrSBe-SO). This scale consists of 17 items on which higher scores represent higher levels of self-reported executive dysfunction. Cronbach's $\alpha$ coefficients for this measure are sufficiently high, ranging from .72 to .94 in normative, neurological, and schizophrenia samples. Furthermore, previous data suggest that the scale has strong construct, discriminant, convergent, and ecological validity (Malloy \& Grace, 2005). We transformed the raw scores into $T$-scores and used norm tables from the manual to assess the level of executive dysfunction (Grace \& Malloy, 2001). 


\section{Utrecht Coping List (UCL)}

The UCL is a self-report questionnaire used to measure the use of coping styles for dealing with everyday problems that are not specifically related to brain injury. Each of the 47 items is answered on a 4-point scale, with higher scores indicating more frequent use of a particular coping style. This study focused on the problem-focused coping subscale (UCLPf; e.g., 'tackling a single problem all at once') and the passive reactions subscale (UCLPas; e.g., 'taking refuge in fantasies'), which is one type of emotion-focused coping. These scales should be interpreted independently because, for example, high UCLpf scores do not necessarily correspond to low UCLpas scores. Both subscales consist of 7 items (Schreurs, de van Willege, Brosschot, Tellegen, \& Graus, 1993; Schreurs, van de Willige, Tellegen, \& Brosschot, 1988; Van Baalen et al., 2007). Both scales have shown sufficient internal consistency in the general Dutch population (Cronbach's $\alpha=.78$ and .74 , respectively) and in this study (Cronbach's $\alpha=.84$ and .75 , respectively) (Schreurs et al., 1993).

\section{Life Satisfaction Questionnaire 9 (LiSat-9)}

The LiSat-9 is a generic self-report instrument for measuring quality of life (Fugl-Meyer, Branholm, \& Fugl-Meyer, 1991). The questionnaire consists of 9 items and measures 9 domains of life satisfaction. We were interested in the domain of general life satisfaction, and therefore, we only used the item 'general satisfaction with life'. This item is rated using a 6-point scale on which higher scores indicate a better quality of life. The Dutch translation of the LiSat-9 has been previously used in a study with individuals who had suffered a stroke, and it showed good reliability (Cronbach's $\alpha=.82$; Visser-Meily, Post, Schepers, \& Lindeman, 2005).

\section{Patient Health Questionnaire-9 (PHQ-9)}

The PHQ-9 is a 9-item self-report measure that assesses the nine DSM-IV criteria of depression on a 4-point Likert scale. Scores range from 0 to 27 , with higher scores indicating more severe levels of depressive symptoms (Kroenke, Spitzer, \& Williams, 2001). Cronbach's $\alpha$ for this measure has ranged from .86 to .89 in several samples (Kroenke et al., 2001). The PHQ-9 has also been validated in a sample of individuals with TBI (Fann et al., 2005).

\section{Neuropsychiatric Inventory Questionnaire (NPI-Q)}

The NPI-Q was completed by the SOs (Cummings, 1994; de Jonghe, Kat, Kalisvaart, \& Boelaarts, 2003; Kaufer et al., 2000). The NPI-Q evaluates the following 12 neuropsychiatric domains: Delusions, hallucinations, agitation, dysphoria, anxiety, apathy, irritability, euphoria, disinhibition, aberrant motor behaviour, night time behaviour disturbances, and appetite and eating abnormalities. The reported outcome was the percentage of patients in whom a symptom was present. Content validity, concurrent validity, inter-rater reliability, and test-retest reliability of the NPI-Q have been established (Cummings, 1994, 1997).

\section{Statistical analyses}

Descriptive and frequency analyses of the scores on the questionnaires and neuropsychological tests were performed. 
To study our first aim, we performed four one-sample $t$-tests to investigate differences in the UCLpf and UCLpas between the men and women in the study group and the men and women of the norm group (Schreurs et al., 1988).

To study our second aim, we examined associations between demographics, injury characteristics, coping, executive functioning, depressive symptoms, and quality of life using Pearson product-moment correlation coefficients $(r)$. The influence of injury type on coping was investigated with two independent sample $t$-tests.

To study our third aim, we investigated the influence of coping on the relationships between executive functioning and depressive symptoms and quality of life using multiple regression analyses. We tested for direct, mediation, and moderation effects (Baron \& Kenny, 1986). Significant demographic and injury variables from the correlation analyses were added to the models as covariates. Mediation suggests that executive functioning influences coping, with coping, in turn, influencing outcomes. We first investigated the associations between TMT, Stroop, and FrSBe-P and UCLpf and UCLpas. Second, we investigated the associations between UCLpf and UCLpas and LiSat-9 and PHQ-9. Only statistically significant predictors were used in the next regression models. Third, we investigated the associations between TMT, Stroop, and FrSBe-P and LiSat-9 and PHQ-9, once with and once without controlling for possible mediators (i.e., UCLpas and/ or UCLpf). We found evidence for (partial) mediation when the regression coefficients for TMT, Stroop, and/or FrSBe-P were substantially reduced ( $>10 \%)$ after controlling for UCLpas or UCLpf. Moderation suggests that certain coping strategies are more or less adaptive for those with different levels of executive functioning. We investigated the influences of the interactions between scores on the TMT, Stroop, and FrSBe-P and UCLpas and UCLpf on LiSat-9 and PHQ-9 scores. In these models, we found evidence for moderation when the interaction term was significant.

All variables, except for gender and education, were entered as continuous variables. $p<.05$ were considered to be statistically significant. For each model, the assumptions for regression analysis were checked. All statistical analyses were conducted using SPSS 22.0 for Mac OS X.

\section{Results}

The results from the measurement instruments are shown in Table 2. Seventy-two percent of all patients reported a low quality of life, as measured with the LiSat-9 (i.e., score 0-4). Scores on the PHQ-9 indicated that, on average, participants showed mild depressive symptoms (score 9), with $43 \%$ reporting moderate to severe symptoms (i.e., score 10-27). The mean TMT score was $2.4(S D=1.0)$, which is below the cut-off of 3 . However, $20 \%$ of the participants had a score higher than 3, indicating difficulties with mental flexibility (Arbuthnott \& Frank, 2000). The mean Stroop score was 54.1 $(S D=35.5)$, representing below average performance, and $21 \%$ of the participants exhibited very poor performance $(<-2 S D$; Schmand et al., 2003). Thirty-one percent of the patients had a score higher than 3 on the TMT or lower than $2 S D$ from the mean of the norm group on the Stroop. FrSBe-P scores indicated that $63 \%$ of the patients subjectively reported clinically significant levels of executive dysfunction. Of the patients with good performance on the Stroop and TMT, 56\% and 60\% reported clinically significant levels of executive dysfunction, respectively. There were no significant associations between the executive measurement instruments $(p>.05)$. However, there was a significant correlation between the FrSBe-SO and FrSBe-P $(r=.36, p<.01)$. The most frequently 
Table 2. Questionnaires' characteristics $(N=93)$

\begin{tabular}{lcc}
\hline & Mean $(S D)$ & Range \\
\hline UCLpf & $16.8(4.2)$ & $8-27$ \\
UCLpas & $15.1(4.2)$ & $7-23$ \\
LiSat-9 & $3.7(1.4)$ & $1-6$ \\
PHQ-9 & $8.8(5.9)$ & $0-24$ \\
TMT ratio $(n=86)$ & $2.4(0.9)$ & $1.0-6.3$ \\
Stroop interference $(n=85)$ & $54.1(35.5)$ & $6.5-185.5$ \\
FrSBe-P $(n=89)$ & $43.2(10.0)$ & $19-65$ \\
FrSBe-SO $(n=58)$ & $43.7(12.0)$ & $17-66$ \\
NPI-Q & $43.2(10.0)$ & $19-65$ \\
NPI-Q & Frequency (\%) \\
Delusions & $9(10)$ & \\
Hallucinations & $4(4)$ & \\
Agitation/aggression & $26(28)$ & \\
Depression & $37(40)$ & \\
Anxiety & $25(27)$ & \\
Euphoria & $22(24)$ & \\
Apathy & $24(26)$ & \\
Disinhibited behaviour & $25(27)$ & \\
Irritability & $46(50)$ & \\
Aimless repetitive behaviour & $14(15)$ & \\
Nocturnal behaviour & $25(27)$ & \\
Appetite & $25(27)$ & \\
\hline
\end{tabular}

Note. UCLpf, Utrecht Coping List - problem-focused scale; UCLpas, Utrecht Coping List - passive scale; LiSat-9, Life Satisfaction Questionnaire; PHQ-9, Patient Health Questionnaire-9; TMT, Trail Making Test; Stroop, Stroop Colour Word Test; FrSBe-P, Frontal Systems Behavioural Scale-completed by patient; FrSBe-SO, Frontal Systems Behavioural Scale-completed by significant other; NPI-Q, Neuropsychiatric Inventory Questionnaire.

reported neuropsychiatric symptoms on the NPI-Q were irritability (50\%), depression (40\%), and aggression (28\%).

\section{Differences in coping styles between patients and the general population}

Overall, patients reported the use of UCLpf less often than a norm group (men: $t_{62}=2.69$, $p<.01$; women: $t_{29}=3.18, p<.01$ ) and used UCLpas more often than a norm group (men: $t_{62}=7.40, p<.001$; women: $t_{29}=6.82, p<.001$ ) (Schreurs et al., 1988, 1993).

\section{Associations between demographic and injury characteristics and measurements}

Correlation analyses showed that older age was significantly associated with lower FrSBeP scores $(r=-.27, p<.05)$, lower UCLpas scores $(r=-.34, p<.01)$, and lower PHQ-9 scores $(r=-.30, p<.01)$. Higher education was significantly associated with lower scores on the TMT, indicating better performance $(r=-.31, p<.01)$, and higher UCLpf scores $(r=.27, p<.05)$. A longer time since injury was associated with higher UCLpf scores $(r=.24, p<.05)$. There was a significant effect of injury type on PHQ-9, with patients with TBI reporting higher scores on the PHQ-9 $\left(\beta=-2.82, t_{90}=2.12, p<.05\right)$. 
However, this effect disappeared after controlling for demographic variables; thus, it was not included in the regression analyses. Gender was not associated with outcomes.

\section{Direct, mediated, and moderated associations between coping, executive functioning, depressive symptoms, and quality of life}

Scores on the TMT and Stroop were not significantly associated with coping. The FrSBe-P was associated with coping, with higher scores on the FrSBe-P predicting lower scores on UCLpf and higher scores on UCLpas $\left(\beta=-.45, t_{84}=3.2, p<.01 ; \beta=.37, t_{84}=3.0\right.$, $p<.01$, respectively).

In contrast with UCLpf scores, scores on UCLpas were predictive of scores on the LiSat9 and PHQ-9. Higher scores on UCLpas were associated with lower LiSat-9 scores and higher PHQ-9 scores $\left(\beta=-.57, t_{87}=5.58, p<.001\right.$; and $\beta=.65, t_{87}=7.0, p<.001$, respectively).

Tests for mediation effects of coping on the associations between executive functioning and depressive symptoms and quality of life showed that FrSBe-P was associated with scores on the LiSat-9 and PHQ-9. In other words, higher scores on the FrSBe-P were associated with lower scores on the LiSat-9 and higher scores on the PHQ-9 $\left(\beta=-.29, t_{84}=2.73, p<.01 ;\right.$ and $\beta=.43, t_{84}=4.44, p<.001$, respectively). The association between FrSBe-P and LiSat-9 was no longer significant after including UCLpas, and the $\beta$ changed from -.29 to -.05 . This result represents an $82 \%$ change, indicating the presence of partial mediation. The association between FrSBe-P and PHQ-9 was still significant after entering UCLpas. However, the $\beta$ changed from .43 to .20 , a $53 \%$ change, indicating partial mediation. In other words, higher scores on the FrSBe-P predicted higher scores on UCLpas, with UCLpas in turn predicting lower scores on the LiSat-9 and higher scores on the PHQ-9. The models explained 36\% and $49 \%$ of the variance in LiSat-9 scores and PHQ-9 scores, respectively.

Tests for moderation effects of coping showed one significant interaction term, which was indicative of UCLpf as a moderator. Specifically, we found that UCLpf moderated the relationship between FrSBe-P and LiSat-9 $\left(\beta=-.94, t_{81}=2.21, p<.05\right)$. The influence of FrSBe-P on LiSat-9 was different for individuals who reported using UCLpf more often than for those who reported using UCLpf less often. For those individuals who reported high scores on the FrSBe-P, more frequent use of UCLpf was associated with decreased LiSat-9 scores. Less frequent use of UCLpf was more adaptive for these individuals. In other words, problem-focused coping was associated with a lower quality of life among individuals who reported lower levels of executive functioning and a higher quality of life among individuals who reported higher levels of executive functioning. The model explained $40 \%$ of the variance in quality of life. The interaction between UCLpas and FrSBe-P was not significant.

\section{Discussion}

This study examined 93 individuals who were admitted to outpatient mental health care clinics and 58 of their SOs. The group was characterized by passive coping styles, low quality of life, and depressive symptoms. Executive functioning was impaired in $31 \%$ of the patients, and $63 \%$ of the patients reported executive dysfunction in daily life. Our analyses showed that self-reported executive dysfunction increased the use of passive coping styles and that the use of passive coping, in turn, had a negative impact on quality 
of life and depressive symptoms. In addition, our analyses suggested that the use of a problem-focused coping style was more adaptive for patients who reported fewer difficulties with executive functioning and less adaptive for patients who reported greater difficulties with executive functioning.

In line with previous research by Anson and Ponsford (2006) and Wolters et al. (2011), we found that in the chronic phase post-injury, the use of passive coping styles was related to a lower quality of life and more depressive symptoms. Specifically, passive coping mediated the relationships between self-reported executive dysfunction and both quality of life and depressive symptoms. One explanation for this pattern of findings is that patients with executive dysfunction and behavioural disturbances such as aggression lack the cognitive ability to effectively use problem-focused coping styles. Consequently, they may revert to using passive coping styles when confronted with problems because these passive coping styles do not require intact executive processes (Krpan et al., 2007).

As expected, a problem-focused coping style moderated the relationship between selfreported executive functioning and quality of life. Specifically, we found that the use of problem-focused coping was more adaptive for individuals who reported lower levels of executive dysfunction than for patients who reported higher levels of executive dysfunction. Spitz et al. (2013) also found that the use of adaptive coping strategies moderated the relationship between cognition and self-reported depression. However, infrequent use of adaptive strategies resulted in greater self-reported depression for patients with poor information processing speed. They concluded that individuals with poor information processing speed may benefit most from the use of problem-focused coping (Spitz et al., 2013). We suggest that, unlike executive functioning, information processing speed is not a prerequisite for using problem-focused coping styles. This is in line with the suggestion that good executive functioning is a prerequisite for problemfocused coping (Krpan et al., 2007). Thus, individuals who report difficulty in performing tasks that recruit executive processes but still revert to the use of problem-focused coping styles may often be unsuccessful in resolving stressful situations that arise in everyday life. Such individuals may be called 'non-successful copers', and problem-focused coping strategies may need to be modified to compensate for their deficits. 'Successful copers' are those individuals who subjectively report few executive deficits in daily life and tend to use problem-focused coping. It can also be suggested that other successful copers are those individuals who subjectively report high levels of executive deficits and use other coping strategies instead of problem-focused coping, such as seeking social or emotional support or accepting problems.

Inconsistent associations between performance on executive functioning tests and the use of different coping styles have been shown in previous studies (Krpan et al., 2007; Spitz et al., 2013; Wolters et al., 2011). Accordingly, this study did not find significant relationships between executive functioning performance and coping or outcomes. In contrast, the present study demonstrated that self-reported executive dysfunction was a strong predictor of coping styles and outcomes. More than half of the patients with good executive performance reported deficits in executive functioning in daily life. Many studies have shown that it is difficult to capture executive functioning impairments in daily life with traditional neuropsychological tests. Traditional tests of executive functioning have shown predictive validity for different facets of the construct (Arbuthnott \& Frank, 2000; Van der Elst, Van Boxtel, Van Breukelen, \& Jolles, 2006). In this study, we measured the constructs response inhibition and mental flexibility and found no significant correlations between the measures. Evidence for the concurrent validity of executive measures is scarce. High correlations (above .5) between executive 
measures have only been found between variants on a single test (Mueller \& Dollaghan, 2013). It has been suggested that these tests do not grasp the complex concept of executive functioning in daily life, which may also explain the absence of a relationship with self-reported executive functioning in the present study. Other non-traditional tests such as the Multiple Errands Test have been suggested to be more sensitive for identifying patients who experience executive difficulties in daily life as well as what sort of problems they encounter (Alderman, Burgess, Knight, \& Henman, 2003).

\section{Strengths and limitations}

This study is unique in several aspects. According to our literature review, this is the first study to investigate the influences of coping and executive functioning in individuals with neuropsychiatric symptoms after ABI. In contrast, previous studies have specifically excluded this group of individuals. In addition, our sample is relatively large, considering the difficulty of recruiting these patients.

It is worth noting that we only used two tasks to assess executive functioning. Conclusions can therefore be drawn only for the facets of executive functioning we measured, that is mental flexibility and response inhibition. The TMT and Stroop were administered in all four participating centres as part of standard clinical care and were consequently included in the present study. Unfortunately, in the present study, we were unable to administer non-traditional tests of executive functioning because these tests were not part of standard diagnostic care. The subjective reports obtained from the standardized questionnaire may provide additional information about executive failures in everyday life. A limitation of using subjective measures is that individuals who have impaired awareness may under- or overestimate the degree of their executive functioning deficits. However, we showed in one of our previous studies using the same patient population that in general, the level of awareness was average. This outcome suggests that overall, patients as a group had accurate awareness of their deficits (Smeets et al., 2014). Furthermore, we also found a high correlation between the self-report measures of executive functioning from patients and their SOs in the present study.

We did not report information about injury severity nor did we control for the effects of injury severity on coping or outcome. Unfortunately, because the patients were on average 11 years post-injury, this information was often not available from the medical files. In addition, more than half of the patients had suffered from non-TBI, which would have limited the power of the regression analyses when only information from patients with TBI was included. Furthermore, we would expect that the mediation and moderation analyses would have shown similar relationships regardless of the injury severity of the patients because injury severity has been shown to not be associated with coping or outcome in the chronic phase post-injury (Anson \& Ponsford, 2006; Finset \& Andersson, 2000; Herrmann et al., 2000).

The present study used a cross-sectional design, which prevents drawing causal conclusions. It is possible that individuals who are more depressed are more prone to use passive, emotion-focused coping styles because passive styles do not require actively solving problems but rather focus on regulating emotional reactions to the stressor (Taylor \& Stanton, 2007). We are currently performing a longitudinal study that will enable us to draw inferences of causal relationships between the variables of interest. 


\section{Future directions and clinical implications}

Coping, depressive symptoms, and quality of life may be influenced by other factors that were not investigated in the current study, such as premorbid coping, personality, availability of social support, or financial status. Including these factors in future research may explain variability that was unaccounted for in our analyses. In addition, the relationship between coping and executive functioning should be explored in future research using other multi-faceted executive functioning tests. Because of the impact of neuropsychiatric symptoms on daily life functioning, future studies need to consider neuropsychiatric symptoms other than depression in their outcome assessments, such as aggression and apathy.

The use of different coping styles has been consistently shown to be an important predictor of outcomes after ABI. The current study provides additional evidence for the maladaptive associations between the use of passive coping styles and depressive symptoms and quality of life in individuals with neuropsychiatric symptoms after ABI. Moreover, individuals who use maladaptive coping styles have been shown to benefit less from treatment programmes (Ownsworth \& McFarland, 2004). Therefore, we suggest that coping should be explicitly considered in mental health care. By assessing coping at admission, individuals who use maladaptive coping styles can be identified and monitored over time. These individuals may benefit from tailored treatment in which therapy is directed at prompting the use of more productive coping styles, thereby improving the effectiveness of rehabilitation and, consequently, decreasing depressive symptoms and increasing quality of life for these individuals. In addition, the mediating and moderating role of coping in the relationship between executive functioning and outcomes may be considered when providing rehabilitation. Patients who report greater difficulties with executive functioning in daily life may more often rely on the use of passive coping styles, which are maladaptive. In comparison, problem-focused coping strategies may be more adaptive for individuals who have stronger executive abilities and less useful for individuals who have weaker executive abilities. This phenomenon suggests that patients with weaker executive abilities should not be prompted to use problem-focused coping styles. These patients may profit from other coping styles such as the use of seeking social support or accepting problems.

\section{References}

Alderman, N., Burgess, P. W., Knight, C., \& Henman, C. (2003). Ecological validity of a simplified version of the multiple errands shopping test. Journal of the International Neuropsychological Society, 9, 31-44. doi:10.1017/S1355617703910046

American Psychiatric Association (2000). Diagnostic and statistical manual of mental disorders DSM-IV-TR Fourth Edition (Text Revision). Arlington, TX: Author.

Anson, K., \& Ponsford, J. (2006). Coping and emotional adjustment following traumatic brain injury. The Journal of Head Trauma Rehabilitation, 21, 248-259. doi:10.1037/t01038-000

Arbuthnott, K., \& Frank, J. (2000). Trail making test, part B as a measure of executive control: Validation using a set-switching paradigm. Journal of Clinical and Experimental Neuropsychology, 22, 518-528. doi:10.1076/1380-3395(200008)22:4;1-0;ft518

Baron, R. M., \& Kenny, D. A. (1986). The moderator-mediator variable distinction in social psychological research: Conceptual, strategic, and statistical considerations. Journal of Personality and Social Psychology, 51, 1173-1182. doi:10.1037/0022-3514.51.6.1173

Benedictus, M. R., Spikman, J. M., \& van der Naalt, J. (2010). Cognitive and behavioral impairment in traumatic brain injury related to outcome and return to work. Archives of Physical Medicine and Rebabilitation, 91, 1436-1441. doi:10.1016/j.apmr.2010.06.019 
Bennett, P. C., Ong, B., \& Ponsford, J. (2005). Assessment of executive dysfunction following traumatic brain injury: Comparison of the BADS with other clinical neuropsychological measures. [Comparative Study]. Journal of the International Neuropsychological Society, 11, 606-613. doi:10.1017/S1355617705050721

Boelen, D. H., Spikman, J. M., Rietveld, A. C., \& Fasotti, L. (2009). Executive dysfunction in chronic brain-injured patients: Assessment in outpatient rehabilitation. Neuropsychological Rebabilitation, 19, 625-644. doi:10.1080/09602010802613853

Bryant, R. A., O'Donnell, M. L., Creamer, M., McFarlane, A. C., Clark, C. R., \& Silove, D. (2010). The psychiatric sequelae of traumatic injury. American Journal of Psychiatry, 167, 312-320. doi:10.1176/appi.ajp.2009.09050617

Burgess, P. W., Alderman, N., Evans, J., Emslie, H., \& Wilson, B. A. (1998). The ecological validity of tests of executive function. Journal of the International Neuropsychological Society, 4, 547558. doi:10.1017/S1355617798466037

Burgess, P. W., Alderman, N., Forbes, C., Costello, A., Coates, L. M., Dawson, D. R., ... Channon, S. (2006). The case for the development and use of "ecologically valid" measures of executive function in experimental and clinical neuropsychology. Journal of the International Neuropsychological Society, 12, 194-209. doi:10.1017/s1355617706060310

Consensus Conference (1999). Rehabilitation of persons with traumatic brain injury. NIH consensus development panel on rehabilitation of persons with traumatic brain injury. Journal of the American Medical Association, 282, 974-983. doi:10.1001/jama.282.10.974

Cummings, J. L. (1994). The Neuropsychiatric Inventory: Comprehensive assessment of psychopathology in dementia. Neurology, 44, 2308-2314. doi:10.1212/WNL.44.12.2308

Cummings, J. L. (1997). The Neuropsychiatric Inventory: Assessing psychopathology in dementia patients. Neurology, 48, S10-S16. doi:10.1212/WNL.48.5_Suppl_6.10S

Dawson, D. R., Schwartz, M. L., Winocur, G., \& Stuss, D. T. (2007). Return to productivity following traumatic brain injury: Cognitive, psychological, physical, spiritual, and environmental correlates. Disability and Rebabilitation, 29, 301-313. doi:10.1080/09638280600756687

De Bie, S. E. (1987). Standard questions 1987: Proposal for uniformization of questions regarding background variables and interviews. Leiden, the Netherlands: Leiden University Press.

de Jonghe, J. F., Kat, M. G., Kalisvaart, C. J., \& Boelaarts, L. (2003). Neuropsychiatric inventory questionnaire (NPI-Q): A validity study of the Dutch form. Tijdschrift voor Gerontologie en Geriatrie, 34, 74-77.

Fann, J. R., Bombardier, C. H., Dikmen, S., Esselman, P., Warms, C. A., Pelzer, E., ... Temkin, N. (2005). Validity of the Patient Health Questionnaire-9 in assessing depression following traumatic brain injury. The Journal of Head Trauma Rehabilitation, 20, 501-511. doi:10.1097/ 00001199-200511000-00003

Finset, A., \& Andersson, S. (2000). Coping strategies in patients with acquired brain injury: Relationships between coping, apathy, depression and lesion location. Brain Injury, 14, 887905. doi:10.1080/026990500445718

Folkman, S., Lazarus, R. S., Gruen, R. J., \& DeLongis, A. (1986). Appraisal, coping, health status, and psychological symptoms. Journal of Personality and Social Psychology, 50, 571-579. doi:10.1037/0022-3514.50.3.571

Fugl-Meyer, A. R., Branholm, I. B., \& Fugl-Meyer, K. S. (1991). Happiness and domain specific life satisfaction in adult northern Swedes. Clinical Rehabilitation, 5, 25-33. doi:10.1177/ 026921559100500105

Godfrey, H. P. D., Knight, R. G., \& Partridge, F. M. (1996). Emotional adjustment following traumatic brain injury: A stress-appraisal-coping formulation. The Journal of Head Trauma Rehabilitation, 11, 29-40. doi:10.1097/00001199-199612000-00006

Gould, K. R., Ponsford, J. L., Johnston, L., \& Schonberger, M. (2011). Relationship between psychiatric disorders and 1-year psychosocial outcome following traumatic brain injury. The Journal of Head Trauma Rehabilitation, 26, 79-89. doi:10.1097/HTR.0b013e3182036799

Grace, J., \& Malloy, P. F. (2001). Frontal systems behavior scale (FrSBe): Professional manual. Lutz, FL: Psychological Assessment Resources. 
Hanna-Pladdy, B. (2007). Dysexecutive syndromes in neurologic disease. Journal of Neurologic Physical Therapy, 31, 119-127. doi:10.1097/NPT.0b013e31814a63c2

Herrmann, M., Curio, N., Petz, T., Synowitz, H., Wagner, S., Bartels, C., \& Wallesch, C. W. (2000). Coping with illness after brain diseases - A comparison between patients with malignant brain tumors, stroke, Parkinson's disease and traumatic brain injury. Disability and Rehabilitation, $22,539-546$.

Johnston, M. V., \& Hall, K. M. (1994). Outcomes evaluation in TBI Rehabilitation. Part I: Overview and system principles. Archives of Physical Medicine and Rehabilitation, 75, SC1-SC9.

Kaufer, D. I., Cummings, J. L., Ketchel, P., Smith, V., MacMillan, A., Shelley, T., ... DeKosky, S. T. (2000). Validation of the NPI-Q, a brief clinical form of the Neuropsychiatric Inventory. Journal of Neuropsychiatry and Clinical Neurosciences, 12, 233-239. doi:10.1176/appi.neuropsych. 12.2 .233

Kegel, J., Dux, M., \& Macko, R. (2014). Executive function and coping in stroke survivors. NeuroRehabilitation, 34, 55-63. doi:10.3233/nre-131010

Kendall, E., \& Terry, D. J. (1996). Psychosocial adjustment following closed head injury: A model for understanding individual differences and predicting outcome. [Peer Reviewed Journal]. Neuropsychological Rehabilitation, 6, 101-132. doi:10.1080/713755502

Kroenke, K., Spitzer, R. L., \& Williams, J. B. (2001). The PHQ-9: Validity of a brief depression severity measure. Journal of General Internal Medicine, 16, 606-613. doi:10.1046/j.1525-1497.2001. 016009606.x

Krpan, K. M., Levine, B., Stuss, D. T., \& Dawson, D. R. (2007). Executive function and coping at oneyear post traumatic brain injury. Journal of Clinical and Experimental Neuropsychology, 29, 36-46. doi:10.1080/13803390500376816

Malloy, P., \& Grace, J. (2005). A review of rating scales for measuring behavior change due to frontal systems damage. Cognitive and Behavioral Neurology, 18, 18-27. doi:10.1097/01.wnn. 0000152232.47901 .88

Moore, A. D., \& Stambrook, M. (1995). Cognitive moderators of outcome following traumatic brain injury: A conceptual model and implications for rehabilitation. Brain Injury, 9, 109-130. doi: $10.3109 / 02699059509008185$

Mueller, J. A., \& Dollaghan, C. (2013). A systematic review of assessments for identifying executive function impairment in adults with acquired brain injury. Journal of Speech, Language, and Hearing Research, 56, 1051-1064. doi:10.1044/1092-4388(2012/12-0147

Ownsworth, T., \& McFarland, K. (2004). Investigation of psychological and neuropsychological factors associated with clinical outcome following a group rehabilitation programme. Neuropsychological Rehabilitation, 14, 535-562. doi:10.1080/09602010343000538

Ponsford, J., Draper, K., \& Schonberger, M. (2008). Functional outcome 10 years after traumatic brain injury: Its relationship with demographic, injury severity, and cognitive and emotional status. [Article]. Journal of the International Neuropsychological Society, 14, 233-242. doi: $10.1017 / \mathrm{s} 1355617708080272$

Rabin, L. A., Barr, W. B., \& Burton, L. A. (2005). Assessment practices of clinical neuropsychologists in the United States and Canada: A survey of INS, NAN, and APA Division 40 members. Archives of Clinical Neuropsychology, 20, 33-65. doi:10.1016/j.acn.2004.02.005

Rao, V., \& Lyketsos, C. (2000). Neuropsychiatric sequelae of traumatic brain injury. Psychosomatics, 41, 95-103. doi:10.1176/appi.psy.41.2.95

Schmand, B., Houx, P., \& de Koning, I. (2003). The Stroop colour word test, the Trail Making Test, the Rivermead, Behavioural Memory Test, Dutch norms. Netherlands Institute of Psychologists, Section Neuropsychology. Retrieved from http://www.psynip.nl

Schreurs, P. J. G., de van Willege, G., Brosschot, J. F., Tellegen, B., \& Graus, G. M. H. (1993). The Utrecht coping list: UCL. Dealing with problems and events. Amsterdam, the Netherlands: Pearson.

Schreurs, P. J. G., van de Willige, G., Tellegen, B., \& Brosschot, J. F. (1988). The Utrecht coping list: Manual of the UCL. Lisse, the Netherlands: Swets \& Zeitlinger. 
Smeets, S. M. J., Ponds, R. W. H. M., Wolters Gregório, G., Pouwels, C. G. J. G., Visscher, A. J., Winkens, I., \& van Heugten, C. M. (2014). Impaired awareness of deficits in individuals with neuropsychiatric symptoms after acquired brain injury: Associations with treatment motivation and depressive symptoms. Neuropsychology, 28, 717-725. doi:10.1037/neu0000068

Spitz, G., Ponsford, J. L., Rudzki, D., \& Maller, J. J. (2012). Association between cognitive performance and functional outcome following traumatic brain injury: A longitudinal multilevel examination. Neuropsychology, 26, 604-612. doi:10.1037/a0029239

Spitz, G., Schonberger, M., \& Ponsford, J. (2013). The relations among cognitive impairment, coping style, and emotional adjustment following traumatic brain injury. The Journal of Head Trauma Rehabilitation, 28, 116-125. doi:10.1097/HTR.0b013e3182452f4f

Spreen, O., \& Strauss, E. (1998). A compendium of neuropsychological tests: Administration, norms, and commentary (2nd ed.). New York, NY: Oxford University Press.

Stroop, J. (1935). Studies in interference in serial verbal reactions. Journal of Experimental Psychology, 18, 643-662. doi:10.1037/h0054651

Taylor, S. E., \& Stanton, A. L. (2007). Coping resources, coping processes, and mental health. Annual Review of Clinical Psychology, 3, 377-401. doi:10.1146/annurev.clinpsy.3.022806.091520

Tombaugh, T. N. (2004). Trail Making Test A and B: Normative data stratified by age and education. Archives of Clinical Neuropsychology, 19, 203-214. doi:10.1016/S0887-6177(03)00039-8

Valentijn, S. A., van Boxtel, M. P., van Hooren, S. A., Bosma, H., Beckers, H. J., Ponds, R. W., \& Jolles, J. (2005). Change in sensory functioning predicts change in cognitive functioning: Results from a 6-year follow-up in the Maastricht aging study. Journal of the American Geriatrics Society, 53, 374-380. doi:10.1111/j.1532-5415.2005.53152.x

Van Baalen, B., Ribbers, G. M., Medema-Meulepas, D., Pas, M. S., Odding, E., \& Stam, H. J. (2007). Being restricted in participation after a traumatic brain injury is negatively associated by passive coping style of the caregiver. Brain Injury, 21, 925-931. doi:10.1080/02699050701553197

Van der Elst, W., Van Boxtel, M. P., Van Breukelen, G. J., \& Jolles, J. (2006). The Stroop color-word test: Influence of age, sex, and education; and normative data for a large sample across the adult age range. Assessment, 13, 62-79. doi:10.1177/1073191105283427

Visser-Meily, A., Post, M., Schepers, V., \& Lindeman, E. (2005). Spouses' quality of life 1 year after stroke: Prediction at the start of clinical rehabilitation. Cerebrovascular Diseases, 20, 443-448. doi: $10.1159 / 000088983$

Wolters, G., Stapert, S., Brands, I., \& van Heugten, C. (2010). Coping styles in relation to cognitive rehabilitation and quality of life after brain injury. Neuropsychological Rehabilitation, 20, $587-$ 600. doi:10.1080/09602011003683836

Wolters, G., Stapert, S., Brands, I., \& van Heugten, C. (2011). Coping following acquired brain injury: Predictors and correlates. The Journal of Head Trauma Rehabilitation, 26, 150-157. doi:10.1097/HTR.0b013e3181e421dc

Wood, R. L. L., \& Rutterford, N. A. (2006). Demographic and cognitive predictors of long-term psychosocial outcome following traumatic brain injury. Journal of the International Neuropsychological Society, 12, 350-358. doi:10.1017/S1355617706060498

Received 22 July 20 I4; revised version received I I December 20 I4 